\title{
PRIMITIVE NEUROECTODERMAL TUMOR OF URINARY BLADDER
}

\section{T. Jagadeeshwar ${ }^{1}$, G. Ravichandar², B. Santosh ${ }^{3}$, N. Srinivas ${ }^{4}$, K. V. Narendra ${ }^{5}$}

\section{HOW TO CITE THIS ARTICLE:}

T. Jagadeeshwar, G. Ravichandar, B. Santosh, N. Srinivas, K. V. Narendra. "Primitive Neuro Ectodermal Tumor of Urinary Bladder". Journal of Evolution of Medical and Dental Sciences 2014; Vol. 3, Issue 73, December 25; Page: 15465-15468, DOI: $10.14260 /$ jemds/2014/4086

INTRODUCTION: PNET of the urinary bladder is extremely rare. Only 12 cases are reported till now in the world. Primitive Neuro Ectodermal Tumor (PNET) is a malignant small round blue cell tumor exhibiting a variable degree of neural differentiation, which arises outside the brain, spinal cord and sympathetic nervous system.(1,2) PNET is a very aggressive tumor with rapid local infiltration combined with widespread metastasis.

KEYWORDS: Haematuria, turbt, ihc: neuron specific enolase, s100 and synaptophysin, rhabdomyo sarcoma and lymphoma.

CASE REPORT: 22Y/M patient came with complaints of difficulty in passing urine, haematuria, since 1 month.He is a known smoker since at age of 15yrs (7yrs); 0/E Palpable mass in lower abdominal area measuring $10 \times 10 \mathrm{~cm}$, not mobile.

INVESTIGATIONS: CUE - haematuria; other Routine investigations are normal. U/S - B/L Hydro ureteronephrosis with thinned out parenchyma with raised s. creatinine with well-defined heterogenous lesions of size $9.7 \times 8.4 \mathrm{cms}$.

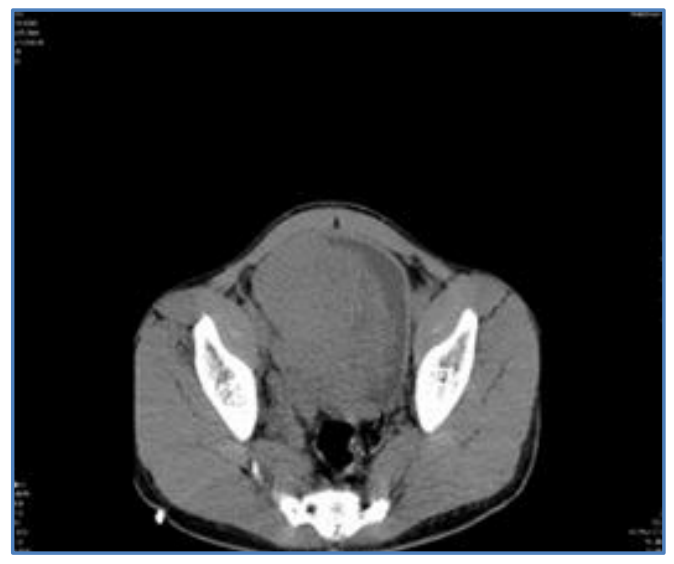

Fig. 1

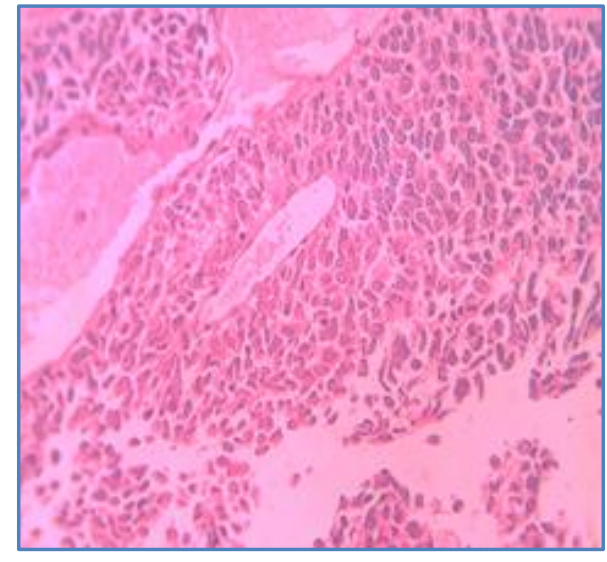

Fig. 2

CECT (Fig. 1): 9x6.7 cms enhancing intra luminal mass noted arising from posterior and lateral wall of urinary bladder with few necrotic areas. No regional / para aortic lymphadenopathy.

Cystoscopic guided biopsy was done and sent for HPE.

\section{PATHOLOGICAL FINDINGS:}

Gross: Received multiple g/w soft tissue bitsall together measuring 4cc.

HPE: Microscopic: Examination (Fig. 2, 3 \& 4 - h \& e) 


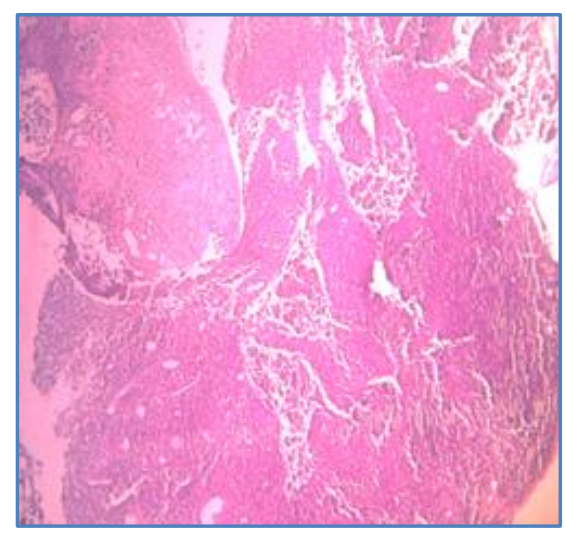

Fig. 3

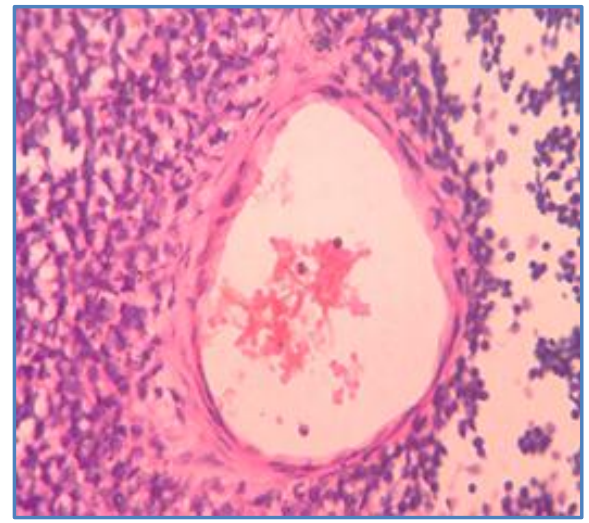

Fig. 4

Sections studied from TURBT specimen, shows native bladder tissue lined focally by transitional epithelium showing stratification. Subepithelial tumor tissue is composed of diffuse sheets and few clusters consisting of predominantly monotonous population of cells. Individual cells are small round to oval shaped, characterized by having scanty cytoplasm with hyper chromaticnucleus. Mild pleomorphism was observed. Few cells show vacuolated cytoplasm. Occasional mitotic activity noted. Peritheliomatous arrangement of tumor cells also seen. Proliferated congested blood vessels observed, with no evidence of necrosis /vascular emboli in the specimen studied.

\section{IHC:}

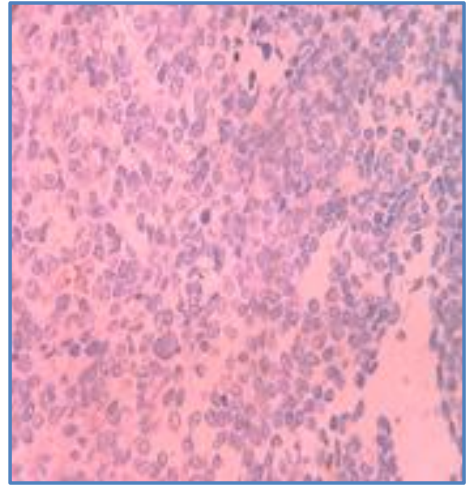

Fig. 5

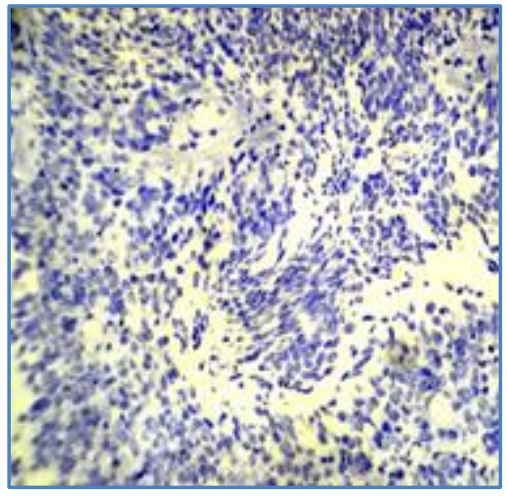

Fig. 6

LCA - Negative (Fig-5)

Desmin - Negative (Fig-6)

Cd-99 - positive (Fig-7)

NSE - positive (Fig-8) 
DISCUSSION: PNET of the Urinary bladder is extremely rare. It is seen in younger age group, Age of our patient noted was 22 yrs with raised s. creatinine so we kept bilateral percutaneous nephrostomy tube drainage and later histologic diagnosis had made and sent for chemoradiation followed by cystectomy and ileal conduit.

IHC analysis, the most useful neural markers are neuron specific enolase, S100 and synaptophysin, with Staining detectable in up to $60 \%$ of the cases.(3) Tumor cells show a strong Expressionof MIC2 protein (CD99). Other immunohistochemical. Markers like, desmin and LCA were negative in our case. There by excluding other D.Ds of small Round cell tumors(2) like Rhabdomyo Sarcoma and Lymphoma. Diagnosis of PNET, in our case was Established by histological and IHC7. Marker positive staining NSE and CD99.

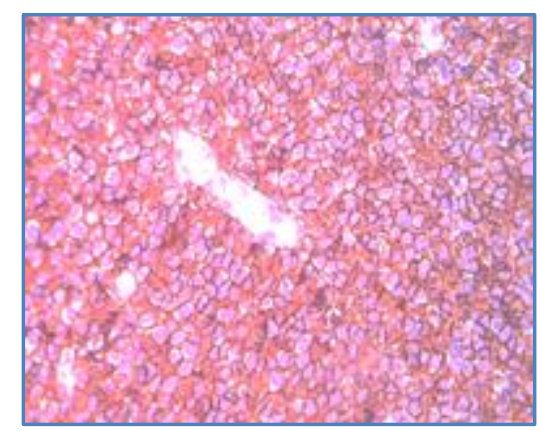

Fig. 7

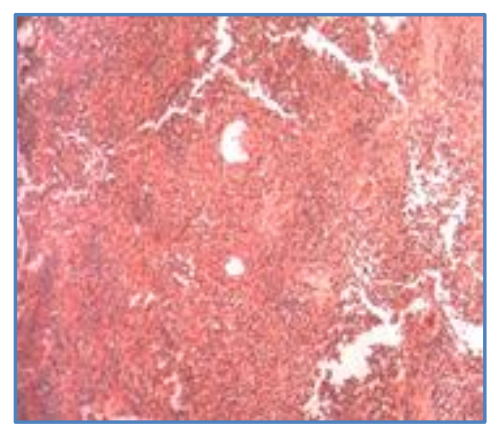

Fig. 8

CONCLUSION: We present rare case of PNET of the urinary bladder, though it is very rare PNET should be considered as one of the D.D of small round cell tumour of the bladder. Confirmatory diagnosis of this tumor signifies the role of IHC. Prompt therapy must be started in view of its highly malignant potential.

\section{REFERENCES:}

1. Ellinger J, Bastian PJ, Hauser S, Biermann K, Müller SC. Primitive neuro ectodermal tumor: Rare, highly aggressive differential diagnosis in urologic malignancies. Urology 2006; 68:257-62.

2. Fletcher CDM. Peripheral neuro ectodermal tumors. In: Franz ME, Sharon W. Weiss (Eds). Soft Tissue Tumors, 3rd Ed Mosby Co St Louis. 1995; 1221-1250.

3. Hernández-Iglesias T, Mackintosh C, de Alava E. Primary primitive neuro ectodermal tumour of the urinary bladder: Aclinico-pathological study emphasising immune histochemical, ultra structural and molecular analyses. J Clin Pathol 2006; 59:775-8. 


\section{AUTHORS:}

1. T. Jagadeeshwar

2. G. Ravichandar

3. B. Santosh

4. N. Srinivas

5. K. V. Narendra

\section{PARTICULARS OF CONTRIBUTORS:}

1. HOD and Professor, Department of Urology, Gandhi Medical College, Secundrabad.

2. Assistant Professor, Department of Urology, Gandhi Medical College, Secundrabad.

3. Assistant Professor, Department of Urology, Osmania Medical College, Secundrabad.
4. Senior Consultant, Department of Urology, Care Hospital, Secundrabad

5. Post Graduate, Department of Urology, Gandhi Medical College, Secundrabad.

\section{NAME ADDRESS EMAIL ID OF THE CORRESPONDING AUTHOR:}

Dr. T. Jagadeeshwar, Professor and HOD, Department of Urology, Gandhi Medical College, Secunderbad-500002.

Email: tseizo1987@gmail.com

Date of Submission: 27/11/2014. Date of Peer Review: 28/11/2014. Date of Acceptance: 18/12/2014. Date of Publishing: 24/12/2014. 